\title{
Serum microRNA 143 and microRNA 215 as potential biomarkers for the diagnosis of chronic hepatitis and hepatocellular carcinoma
}

\author{
Zhu-qing Zhang ${ }^{1}$, Hua Meng ${ }^{2}$, Nan Wang ${ }^{3}$, Li-na Liang ${ }^{2}$, Li-na Liu², Shu-ming Lu² ${ }^{2 *}$ and Yong Luan ${ }^{4^{*}}$
}

\begin{abstract}
Background: Hepatocellular carcinoma (HCC) is regarded as one of the most common malignancies and among the leading causes of cancer death among the whole world. The most urgent needs are to find sensitive markers for early diagnosis or monitor postoperative recurrence and to give adequate treatment for HCC. MicroRNAs (miRNAs) are reported as a group of small non-coding RNAs that can function as endogenous RNA interference to regulate expression of the targeted genes. This study was conducted to detect the application of miR-143 and miR-215 in the diagnosis of HCC.
\end{abstract}

Methods: A total of 340 serum samples (127 samples from controls, 118 samples from hepatitis and 95 samples from HCC patients) were collected. The levels of the two mature miRNAs (miR-143 and miR-215) were detected by probe-based stem-loop quantitative reverse-transcriptase PCR (RT-qPCR) in controls, hepatitis and HCC patients. Besides, the relationship between miR-143 and miR-215 levels and clinical and pathological factors was explored.

Results: We found that the expression of serum miR-215 was distinctly increased in chronic hepatitis compared with controls (mean \pm SD: $6.79 \pm 0.72$ vs. $3.46 \pm 0.37, P<0.001$ and mean \pm SD: $8.38 \pm 0.87$ vs. $3.46 \pm 0.37, P<0.001$ ). In addition, we conduct ROC analyses to detect the potential application of miR-143 and miR-215 in the diagnosis of chronic hepatitis and HCC. Our results showed that miR-143 and miR-215 might be a potential biomarker for the hepatitis and HCC.

Conclusions: In conclusion, the expression of miR-143 and miR-215 in serum were significantly up-regulated in patients with chronic hepatitis and HCC. Due to its reasonable sensitivity and specificity for both diseases, miR-143 and miR-215 could be as potential circulating biomarkers.

Virtual Slides: The virtual slide(s) for this article can be found here: http://www.diagnosticpathology.diagnomx.eu/ vs/1048932281272754

\section{Background}

Hepatocellular carcinoma (HCC) is regarded as one of the most common malignancies and among the leading causes of cancer-related deaths among the whole world, especially in East Asia and South Africa [1,2]. HCC ranks the second in China among all malignancies and its mortality is almost equal to its morbidity [3,4]. The carcinogenesis of HCC is a multifactor, multi-step, complex

\footnotetext{
*Correspondence: yonglu_09@163.com; yongluango@163.com

${ }^{2}$ Department of Gastroenterology, the First Affiliated Hospital of Dalian

Medical University, Dalian 116011, China

${ }^{4}$ Department of Anesthesiology, the First Affiliated Hospital of Dalian Medical University, Dalian 116011, China

Full list of author information is available at the end of the article
}

process and it is associated with a background of chronic liver diseases or persistent infection of hepatitis $\mathrm{B}$ virus (HBV) or hepatitis C virus (HCV), along with alcohol drinking which are widely recognized etiological agents in HCC. However, the underlying mechanisms that lead to malignant transformation of infected cells remained unclear by now. Most HCC patients died quickly because of the rapid tumor progression and hepatic resection or transplantation is the only potential curative treatment for HCC patients. By now, surgery remains the best prognostic tool for long-term survival of HCC patients; however, more than $80 \%$ of patients with HCC have underlying cirrhosis, and of these patients, only $10 \%$ to $15 \%$ are 
potentially resectable. The rest are unresectable because of size, location or severity of underlying liver disease. The most urgent needs are to find sensitive markers for early diagnosis or monitor postoperative recurrence and to give adequate treatment for HCC.

Up to now, although serum alpha-fetoprotein (AFP) level is a useful tumor marker for the detection and monitoring of $\mathrm{HCC}$, the false negative rate with AFP level alone may be as high as $40 \%$ for patients with early stage HCC. Even in the patients with advanced HCC, the AFP levels may remain normal in $15 \sim 30 \%$ of all the patients [5]. New specific markers, such as homeobox gene Barx2, SMG-1, GOLM1 and et al. [6-8] have been developed to improve the sensitivity, specificity, early detection and prediction of prognosis of HCC. However, the overall results have been unsatisfactory [9].

MicroRNAs (miRNAs) are reported as a group of small non-coding RNAs that can function as endogenous RNA interference to regulate expression of the targeted genes [10-12]. To date, more than 1000 human miRNAs have been identified and reported in the RNA database. Considering taht altered expression of some miRNAs contributes to human carcinogenesis, a part of these miRNAs have been reported to be useful as potential biomarkers for diagnosis, prognosis, and personalized therapy of human cancers [13-15]. For example, aberrant miRNA expression has been reported in HCC patients or cell lines $[16,17]$. Given that blood samples can be easily obtained and have the advantages of minimally invasive continuous in vitrotesting and high reproducibility, determining disease-specific circulating miRNAs to predict and diagnose HCC has become the focus of many studies. A number of researchers have reported the potential clinical application of circulating miRNAs (such as miR-122, miR125b-5p, miR-223-3p, miR-15b and miR-130b) in the diagnosis and prognosis of HCC [18-21]. Thus, further investigation of aberrant miRNA expression could lead to the discovery of novel miRNA biomarkers for HCC.

The objective of this study was to determine whether altered miR-143 and miR-215 expression detected in the serum could be a useful biomarker for the diagnosis of HCC. Real-time quantitative reverse transcription polymerase chain reaction (RT-qPCR) was performed with the following two goals of exploring whether: [1] serum miR-143 and miR-215 are abnormally expressed in hepatitis and HCC; [2] miR-143 and miR-215 expression in serum might diagnose hepatitis and HCC.

\section{Methods}

\section{Ethics statement}

Written informed consents were obtained from all the participants in this study. The samples were processed under approval of the Human Research Ethics Committee of the Dalian Medical University, Shandong, China. For identification, the samples were codified A (for controls), B (Hepatitis) and C (for HCC) followed by a codified number to protect the privacy of individuals during all the further molecular study.

\section{Patients and samples}

Between January 2013 and October 2013, a total of 340 serum samples (127 samples from controls, 118 samples from hepatitis and 95 samples from HCC patients) were collected at the First Affiliated Hospital of Dalian Medical University and Dalian Municipal Central Hospital. All of the HCC patients were diagnosed by liver biopsy or by the findings of at least two radiological tests of HCC, including abdominal ultrasound, magnetic resonance imaging (MRI), hepatic angiography and contrast-enhanced dynamic computed tomography or by increased AFP (AFP $\geq 200 \mu \mathrm{g} / \mathrm{mL}$ ). Patients with secondary or recurrent tumors, a history of other malignant tumors or being included in other studies were excluded from this study. For the 118 chronic hepatitis cases, the diagnosis was based on the serum test. Serum hepatitis B surface antigens (HBsAg) and anti-HCV antibody were assayed by microparticle enzyme immunoassay using commercial kits to determine hepatitis $B$ or hepatitis $C$ infection. A total of 127 cancer-free controls were attached at the physical examination center in the First Affiliated Hospital of Dalian Medical University and matched with cases by age within 5 years and sex. Controls that had clinical liver diseases were excluded.

All subjects were asked to fill a questionnaire to investigate the demographic characteristics, disease history and the history of cancer and alcohol or tobacco use. The clinical characteristics including tumor differentiation, tumor size, metastasis, Child-Pugh class, chemotherapy and surgery were collected from medical records.

\section{RNA extraction}

Total RNA extraction was performed using a miRcute miRNA isolation kit (Tiangen, China), following the manufacturer's protocol for serum/plasma samples. Samples were enriched for miRNAs in the extraction process. The yields of total RNA were about $250 \mathrm{ng}$ per $400 \mathrm{ml}$ of serum. The extracted RNA was reverse transcription to cDNA as soon as possible. Reverse transcription was carried out using an all-in-one miRNA first-strand cDNA synthesis kit (Genecopoeia). The operation was conducted following the manufacturer's protocol for serum/plasma samples.

Real-time PCR quantification of miRNA expression in serum The expressions of miRNAs were quantified by TaqMan miRNA assays (Applied Biosystems) following reverse transcription (Tiangen, Chin) of 40 ng RNA. Reactions were loaded onto a 96-well plate and run in duplicate on 
an ABI 7900 Fast Real-Time PCR System (Applied Biosystems). The reactions were firstly incubated at $50^{\circ} \mathrm{C}$ for 20 seconds and then $95^{\circ} \mathrm{C}$ for 10 minutes, followed by 40 cycles of denaturation at $95^{\circ} \mathrm{C}$ for 15 seconds, then 1 minute of annealing/extension at $60^{\circ} \mathrm{C}$. The $\Delta \Delta C T$ method was used to determine relative number of copies (RQ) of miRNA. The U6 was chosen as the endogenous normalizer. The primers used for qRT-PCR in this study are as following: miR-143: GCTGAGATGAAGCACTG AAGCTC, miR-215: AATATTGGCTAGCAGCACGTA and U6: CAAAGTCAGTGCAGGTAGGCTTA.

\section{Statistical analysis}

The statistical analyses in this study was performed using Statistical Program for Social Sciences (SPSS) software 17.0 (SPSS Inc., Chicago, USA). The t-test between two groups were used to analyze the differences between two groups. Nonparametric tests (the Wilcoxon-MannWhitney test between two groups and the KruskallWallis test for three or more groups) were used to analyze the relationship between the above miRNA expression level and various clinicopathologic characteristics. The receiver operating characteristic curve (ROC) analysis was undertaken using the expression level for each miRNA in the serum from cases and controls to assess the diagnostic accuracy of each parameter. Using this approach, the area under the ROC (AUC) identified optimal sensitivity and specificity levels at which to distinguish normal individuals. All the $P$ values were shown two sided and a $P$ value of $<0.05$ was considered statistically significant.

\section{Results}

Baseline and clinicopathologic characteristics of the patients The baseline and clinicopathologic characteristics of the all the participants are presented in Table 1. The median ages of the control group, chronic hepatitis and HCC patients at diagnosis were $52.58 \pm 6.98$ years, $53.12 \pm 7.24$ years, and $54.21 \pm 6.95$ years. Among the three groups, there are no differences in the rates of hypertension, diabetes, tobacco smoking and alcohol drinking among the three groups $(\mathrm{P}>0.05)$. Among the $95 \mathrm{HCC}$ cases, 49 cases have a size over $5 \mathrm{~cm}$ while the others less than $5 \mathrm{~cm}$. The tumor stages are 37 cases of TNM-I, 29 cases of TNM-II, 26 cases of TNM-III and 13 cases of TNM-IV. The lymph nodes and distant metastasis were observed in 12 and 8 cases, respectively.

\section{MiR-143 and miR-215 expression in chronic hepatitis and HCC}

Serum miR-143 and miR-215 expression were detected in 118 chronic hepatitis cases, 95 HCC cases and 127 controls normalized to RNU6B. As shown in Figure 1, we found that the expression of serum miR-215 was distinctly increased in chronic hepatitis compared with controls
$($ mean \pm SD: $6.79 \pm 0.72$ vs. $3.46 \pm 0.37, \quad \mathrm{P}<0.001)$. The serum miR-143 was also increased in patients with HCC compared with the controls (mean \pm SD: $8.38 \pm 0.87$ vs. $3.46 \pm 0.37, \mathrm{P}<0.001)$. The expression of serum miR-143 in chronic hepatitis $(3.19 \pm 0.51)$ and HCC group (5.13 \pm 0.71 ) are both higher compared with the control group $(1.91 \pm 0.44)(\mathrm{P}<0.001)$.

\section{Diagnostic accuracy of serum miR-143 and miR-215 for chronic hepatitis and HCC}

The ROC curve analysis was used to analyze the diagnostic accuracy of serum miR-143 and miR-215. ROC curve analyses revealed that both serum miR-143 and miR-215 could serve as valuable biomarkers for chronic hepatitis from healthy controls with an AUC (the areas under the ROC curve) of 0.617 (95\% CI: $0.512-0.758$; P = 0.007) and 0.802 (95\% CI: $0.6701-0.947 ; \mathrm{P}=0.0006$ ), respectively (Figures $2 \mathrm{~A}$ and $2 \mathrm{~B}$ ). At the cut-off value less than 2.14 for miR-143, the sensitivity and the specificity were $78 \%$ and $64 \%$, respectively. At the cut-off value less than 4.23 for miR-215, the sensitivity and the specificity were $78 \%$ and $89 \%$, respectively.

When the diagnostic value of miR-143 and miR-215 for HCC were considered, both of the miRNAs are potential biomarkers for the diagnosis of HCC. The results showed that miR-143 and miR-215 could serve as valuable biomarkers for HCC from healthy controls with an AUC (the areas under the ROC curve) of 0.795 (95\% CI: $0.682-$ $0.915 ; \mathrm{P}=0.0001)$ and 0.816 (95\% CI: $0.721-0.973 ; \mathrm{P}<$ 0.0001 ), respectively (Figures $3 \mathrm{~A}$ and $2 \mathrm{~B}$ ). At the cut-off value less than 2.21 for miR-143, the sensitivity and the specificity were $73 \%$ and $83 \%$, respectively. At the cut-off value less than 4.62 for miR-215, the sensitivity and the specificity were $80 \%$ and $91 \%$, respectively.

\section{Discussion}

In this present study, we analyzed the expression of two miRNAs, miR-143 and miR-215, in the serum among the patients with healthy controls, chronic hepatitis and HCC patients. We found that miR-143 and miR-215 expression was up-regulated in the serum samples from patients with chronic hepatitis and HCC compared with the controls. In addition, we conduct ROC analyses to detect the potential application of miR-143 and miR-215 in the diagnoses of chronic hepatitis and HCC. Our results showed that miR-143 and miR-215 might be potential biomarkers for both hepatitis and HCC. Our current data indicated that serum miR-143 and miR-215 expression might be further evaluated as novel noninvasive diagnostic biomarkers for HCC.

A lot of previous studies reported that miRNA expression is aberrant through HCC development; however, most of these studies focused on the expression of miRNAs in HCC tissues and cell lines. For example, a previous study 
Table 1 Characteristics of hepatocellular carcinoma patients, and controls

\begin{tabular}{|c|c|c|c|c|c|}
\hline \multirow[t]{2}{*}{ Clinicopathological features } & \multirow[t]{2}{*}{ No. of participants } & \multicolumn{3}{|c|}{ Groups } & \multirow[t]{2}{*}{$P$} \\
\hline & & Control $(n=127)$ & Hepatitis $(n=118)$ & $\mathrm{HCC}(n=95)$ & \\
\hline Mean age (year,mean \pm SD) & 340 & $52.58 \pm 6.98$ & $53.12 \pm 7.24$ & $54.21 \pm 6.95$ & 0.634 \\
\hline \multicolumn{6}{|l|}{ Gender } \\
\hline Male & 184 & 71 & 65 & 60 & \multirow[t]{2}{*}{0.217} \\
\hline Female & 156 & 56 & 53 & 35 & \\
\hline \multicolumn{6}{|l|}{ Hypertension } \\
\hline No & 120 & 42 & 42 & 36 & \multirow[t]{2}{*}{0.129} \\
\hline Yes & 220 & 85 & 75 & 59 & \\
\hline \multicolumn{6}{|l|}{ Diabetes mellitus } \\
\hline No & 302 & 112 & 105 & 85 & \multirow[t]{2}{*}{0.863} \\
\hline Yes & 38 & 15 & 13 & 10 & \\
\hline \multicolumn{6}{|l|}{ Tobacco smoking } \\
\hline No & 192 & 74 & 68 & 62 & \multirow[t]{2}{*}{0.207} \\
\hline Yes & 148 & 53 & 65 & 33 & \\
\hline \multicolumn{6}{|l|}{ Alcohol consumption } \\
\hline No & 238 & 89 & 82 & 77 & \multirow[t]{2}{*}{0.326} \\
\hline Yes & 102 & 38 & 36 & 22 & \\
\hline \multicolumn{6}{|l|}{ Tumor size $(\mathrm{cm})$} \\
\hline$\geq 5 \mathrm{~cm}$ & & & & 49 & \\
\hline$<5 \mathrm{~cm}$ & & & & 46 & \\
\hline \multicolumn{6}{|l|}{ TNM staging } \\
\hline TNM-I & & & & 37 & \\
\hline TNM-II & & & & 29 & \\
\hline TNM-III & & & & 16 & \\
\hline TNM-IV & & & & 13 & \\
\hline \multicolumn{6}{|l|}{ LN metastasis } \\
\hline No & & & & 83 & \\
\hline Yes & & & & 12 & \\
\hline \multicolumn{6}{|l|}{ Distant metastasis } \\
\hline No & & & & 87 & \\
\hline Yes & & & & 8 & \\
\hline
\end{tabular}

HCC: Hepatocellular carcinoma; LN: Lymph nodes.

focused on microRNA expression profiles in human hepatitis B virus-related HCC. Based on the data of 11 pairs of $\mathrm{HCC}$ and matched non-tumorous tissues from $11 \mathrm{HBV}$ infection patients, miR-96, miR-183, and miR-196a were up-regulated significantly, while let-7c and miR-138 were down-regulated [22]. Xiao et al. conduct a follow-up study and the results revealed that miR-200a was frequently downregulated in HCC. In addition, multivariate analysis confirmed that miR-200a was significantly associated with the overall survival of HCC patients [23]. In an other study, Yu et al. found that miR-424 was down-regulated in HCC cell lines compared a normal hepatocytes and in vitro studies showed that miR-424 is effective in the neoplasty of HCC [24].
Although tissue miRNAs can provide an accurate diagnosis for various types of cancer, the difficulty in collecting tissue samples limits its application for the detection of cancer biomarkers. Acquiring tissue samples is an invasive procedure and depends on surgical sections after initial clinical classification [25]. The search for noninvasive tools for the diagnosis of cancer has long been a goal of many researchers, and much of the interest has been on the circulation of nucleic acids in plasma and serum. Compared with DNA and mRNA, circulating miRNAs show remarkable stability after prolonged incubation at room temperature and/or multiple freezing-thawing processes. However, the protective mechanism of circulating miRNAs is still unknown. Some investigators reported that 


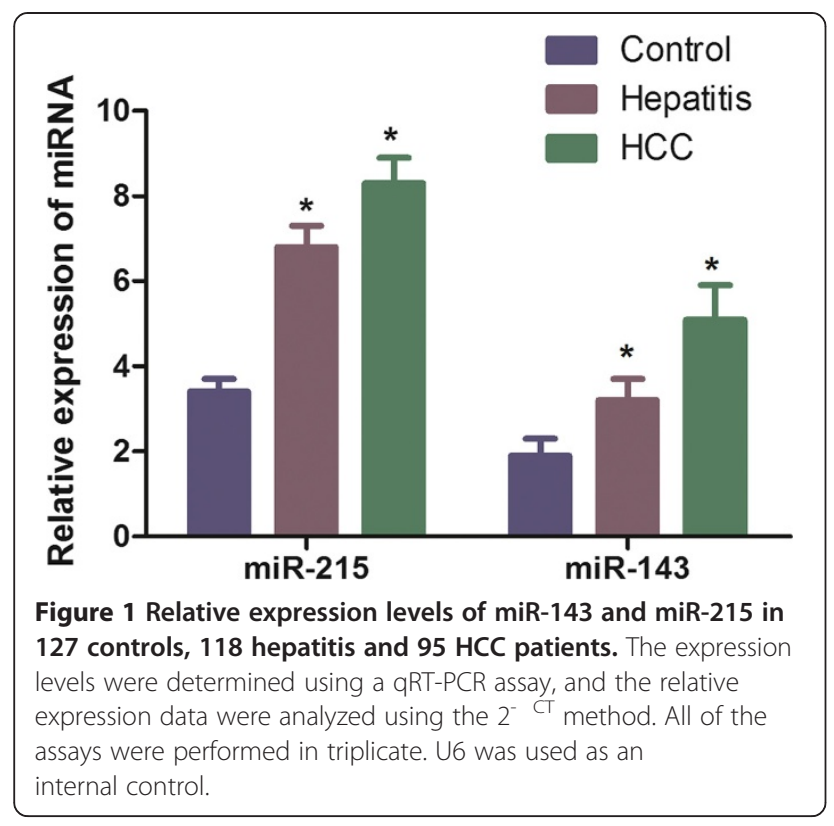

circulating miRNAs were in the form of argonaute 2 (Ago2)-miRNA complexes that could avoid RNase digestion [26].

Nowadays, there are increasing studies being conducted to identify specific circulating miRNAs in the diagnosis of HCC. Giray et al. conducted a study to investigate the potential of certain serum/plasma miRNAs as novel non-invasive biomarkers for early diagnosis of HBV related HCC. Through comprehensive tests of 94 plasma samples (28 control and 66 patient plasma samples), a series of related miRNAs were reported in the study and the expression of miR-223 was the most significant. Microvesicles (MVs) packaged with miRNAs were reported to be released mainly from tumor cells. Sun et al. conduct expression profiles to detect the differently expressed miRNAs. The results showed that a total of 242 aberrantly expressed miRNAs were identified in HCC-MVs compared with CHB-MVs and the control. Among them, 115 miRNAs were up-expressed with up to 31 fold difference (miR-671-5p) and 127 were down-expressed with up to 0.041 fold difference (miR-432) in HCC [27]. A potential correlation was also evaluated between miR-101 expression and the clinicopathological features and prognosis of HCC patients. It was reported that miR-101 was down-regulated in HBV-related HCC tissues compared with adjacent noncancerous tissues. Furthermore, the miR-101 levels in these tissues from HCC patients were significantly lower than those in tissues from control subjects [28].

In this present study, we focus on the diagnostic value of miR-143 and miR-215 for the chronic hepatitis and HCC. Previous reports have shown that the expression of miR-143 is extremely down-regulated in colorectal cancer, lung, bladder, and gastric cancers [29-31]. While it is reported the expression of miR-143 is up-regulated in pancreatic stellate cells cancer and esophageal cancer $[32,33]$. There are few reports about the relationship between miR-143 expression and the diagnosis of HCC. Up to now, only one study reported the association between miR-143 and HCC. Zhang et al. reported that the levels of miRNA-143 (miR-143) are dramatically increased in metastatic HBV-HCC of both $\mathrm{p} 21-\mathrm{HBx}$ transgenic mice and HCC patients. Advanced study showed that up-regulation of miR-143 expression promotes cancer cell invasion/migration and tumor metastasis by repression of FNDC3B expression [34]. The association between
A

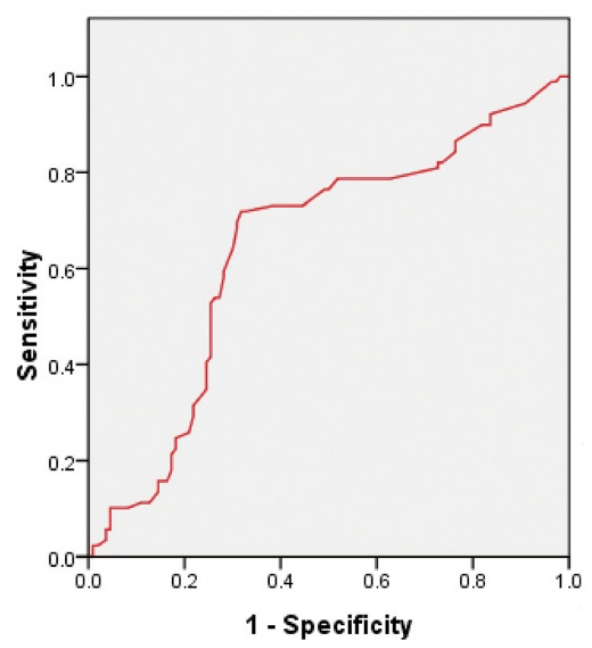

B

$\operatorname{miR}-215$

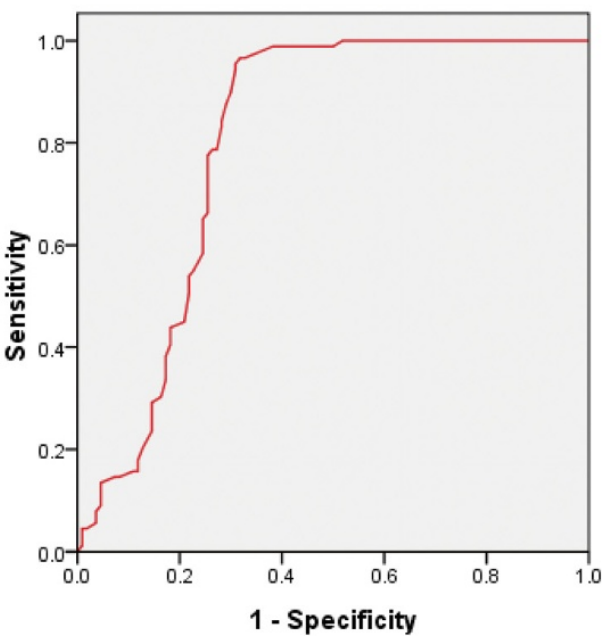

Figure 2 Receiver-operatorcharacteristic (ROC) curves of the A) miR-143 and B) miR-215 for the chronic hepatitis. 
A

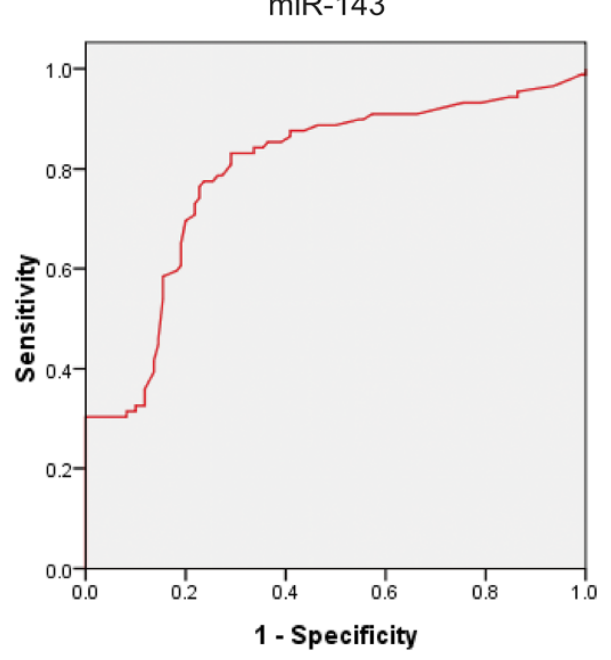

B

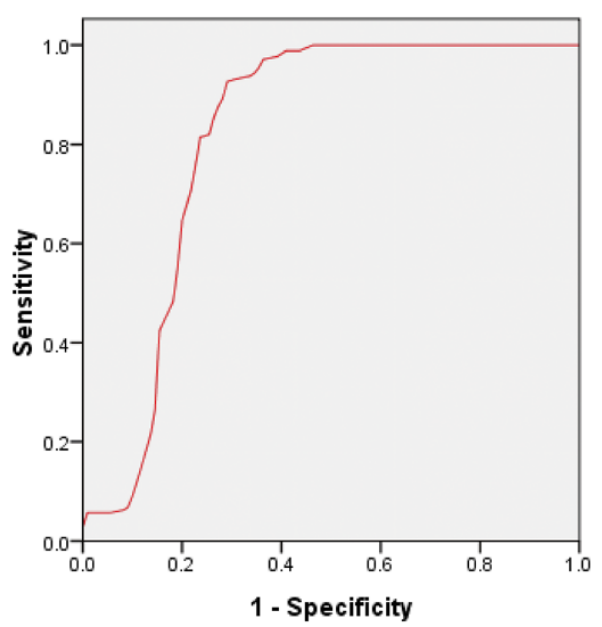

Figure 3 Receiver-operatorcharacteristic (ROC) curves of the A) miR-143 and B) miR-215 for the hepatocellular carcinoma.

miR-215 and cancer were also reported. Senanayake et al. reported that miR-215 had a significantly lower expression in nephroblastomas regardless of the subtype compared with mature kidney measured by quantitative realtime-PCR [35]. White et al. performed experimental and bioinformatic analyses to explore the involvement of miR-215 in renal cell carcinoma progression and metastasis. In vitro study showed that miR-215 might contribute to kidney cancer metastasis through different biological processes [36]. In a previous study, miR-215 was reported to be up-regulated in HCC cancer cases [37]. Ishida et al. reported that using miRNA array analysis, miR-192/miR-215, miR-194, miR-320, and miR-491 were identified as being altered by HCV infection. Among them, miR-192/miR-215 and miR-491 were capable of enhancing replication of the HCV replicon as well as $\mathrm{HCV}$ itself [38]. To our best knowledge, this is the first study that reports the association between miR-143/miR-215 and HCC. More related studies are wanted to investigate to clinical application and detailed mechanisms.

Recent years, more and more studies raised diagnostic and prognostic application of miRNAs in different diseases, including cancer. Their application to body specimens from blood to tissues has been helpful for appreciating their use in the clinical context [39]. Our results showed that serum miR-143 and miR-215 were commonly upregulated in chronic hepatitis and HCC patients, suggesting miR-143 and miR-215 may be new potential diagnostic biomarkers and targets of chronic hepatitis and HCC. However, as a case-control study without a long-time follow-up, the prognostic effect of the two miRNAs could not be detected in this study. A follow-up of this cohort would be reportedand more advanced analyses would be conducted.

\section{Conclusion}

In conclusion, the expression of miR-143 and miR-215 in serum were significantly up-regulated in patients with chronic hepatitis and HCC. Due to its reasonable sensitivity and specificity for both diseases, miR-143 and miR-215 could be as potential circulating biomarkers. Our work will serve as a basis for further investigation, preferably large-scale validation in clinical trials, before serum miRNAs can be used as a routine screening tool for HCC.

\section{Competing interests}

The authors declare that they have no competing interests.

\section{Authors' contributions}

ZQZ, HM, NW, LNL, SML and YL provided the conduction of the whole project, ZQZ, HM, SML and YL drafted the manuscript; ZQZ, HM, LNL, SML and $Y L$ contributed to revise the manuscript. All authors read and approved the final manuscript.

\section{Author details}

'Department of Pathology, Dalian Municipal Central Hospital, Dalian 116033, China. ${ }^{2}$ Department of Gastroenterology, the First Affiliated Hospital of Dalian Medical University, Dalian 116011, China. ${ }^{3}$ Department of Clinical Lab, the First Affiliated Hospital of Dalian Medical University, Dalian 116011, China.

${ }^{4}$ Department of Anesthesiology, the First Affiliated Hospital of Dalian Medical University, Dalian 116011, China.

Received: 17 April 2014 Accepted: 2 June 2014

Published: 2 July 2014

\section{References}

1. Milanizadeh S, Khanyaghma M, Haghighi MM, Mohebbi S, Damavand B, Almasi S, Azimzadeh P, Zali M: Molecular analysis of imperative polymorphisms of MLH1 gene in sporadic colorectal cancer. Cancer Biomark 2013, 13:427-432.

2. Abdel-Wahab M, El-Ghawallby N, Mostafa M, Sultan A, El-Sadany M, Fathy O, Salah T, Ezzat F: Epidemiology of hepatocellular carcinoma in lower Egypt, Mansoura Gastroenterology Center. Hepatogastroenterology 2007, 54:157-162.

3. Bao YX, Cao Q, Yang Y, Mao R, Xiao L, Zhang H, Zhao HR, Wen H: Expression and prognostic significance of Golgiglycoprotein73 (GP73) with Epithelial-mesenchymal transition (EMT) related molecules in Hepatocellular Carcinoma (HCC). Diagn Pathol 2013, 8:197. 
4. Kojiro M, Kawabata K, Kawano Y, Shirai F, Takemoto N, Nakashima T: Hepatocellular carcinoma presenting as intrabile duct tumor growth: a clinicopathologic study of 24 cases. Cancer 1982, 49:2144-2147.

5. Volk ML, Hernandez JC, Su GL, Lok AS, Marrero JA: Risk factors for hepatocellular carcinoma may impair the performance of biomarkers: a comparison of AFP, DCP, and AFP-L3. Cancer Biomark 2007, 3:79-87.

6. Chen MH, Jan YH, Chang PM, Chuang YJ, Yeh YC, Lei HJ, Hsiao M, Huang SF, Huang CY, Chau GY: Expression of GOLM1 correlates with prognosis in human hepatocellular carcinoma. Ann Surg Oncol 2013, 20(Suppl 3):S616-S624.

7. Dogan E, Yalcin S, Koca D, Olmez A: Clinicopathological characteristics of hepatocellular carcinoma in Turkey. Asian Pac J Cancer Prev 2012, 13:2985-2990.

8. Huang J, Deng Q, Wang Q, Li KY, Dai JH, Li N, Zhu ZD, Zhou B, Liu XY, Liu RF, Fei QL, Chen H, Cai B, Xiao HS, Qin LX, Han ZG: Exome sequencing of hepatitis B virus-associated hepatocellular carcinoma. Nat Genet 2012, 44:1117-1121.

9. Zhou G, Chiu D, Qin D, Niu L, Cai J, He L, Tan D, Xu K: Expression of CD44v6 and integrin-beta1 for the prognosis evaluation of pancreatic cancer patients after cryosurgery. Diagn Pathol 2013, 8:146.

10. Hansen TB, Jensen TI, Clausen BH, Bramsen JB, Finsen B, Damgaard CK, Kjems J: Natural RNA circles function as efficient microRNA sponges. Nature 2013, 495:384-388.

11. Su ZX, Zhao J, Rong ZH, Geng WM, Wu YG, Qin CK: Upregulation of microRNA-25 associates with prognosis in hepatocellular carcinoma. Diagn Pathol 2014, 9:47.

12. Gargalionis AN, Basdra EK: Insights in microRNAs biology. Curr Top Med Chem 2013, 13:1493-1502.

13. Zhao J, Lu Q, Zhu J, Fu J, Chen YX: Prognostic value of miR-96 in patients with acute myeloid leukemia. Diagn Pathol 2014, 9:76

14. Liu F, Xiong Y, Zhao Y, Tao L, Zhang Z, Zhang H, Liu Y, Feng G, Li B, He L, Ma J, Qin S, Yang Y: Identification of aberrant microRNA expression pattern in pediatric gliomas by microarray. Diagn Pathol 2013, 8:158.

15. Wang W, Li F, Zhang Y, Tu Y, Yang Q, Gao X: Reduced expression of miR-22 in gastric cancer is related to clinicopathologic characteristics or patient prognosis. Diagn Pathol 2013, 8:102

16. Li Y, Chen L, Chan TH, Guan XY: Hepatocellular carcinoma: transcriptome diversity regulated by RNA editing. Int J Biochem Cell Biol 2013, 45:1843-1848

17. Ronald JA, Katzenberg R, Nielsen CH, Jae HJ, Hofmann LV, Gambhir SS: MicroRNA-regulated non-viral vectors with improved tumor specificity in an orthotopic rat model of hepatocellular carcinoma. Gene Ther 2013, 20:1006-1013.

18. Luo J, Chen M, Huang H, Yuan T, Zhang M, Zhang K, Deng S: Circulating microRNA-122a as a diagnostic marker for hepatocellular carcinoma. Onco Targets Ther 2013, 6:577-583.

19. Liu AM, Yao TJ, Wang W, Wong KF, Lee NP, Fan ST, Poon RT, Gao C, Luk JM: Circulating miR-15b and miR-130b in serum as potential markers for detecting hepatocellular carcinoma: a retrospective cohort study. BMJ Open 2012, 2:e000825.

20. Cui M, Xiao Z, Sun B, Wang Y, Zheng M, Ye L, Zhang X: Involvement of cholesterol in hepatitis $B$ virus $X$ protein-induced abnormal lipid metabolism of hepatoma cells via up-regulating miR-205-targeted ACSL4. Biochem Biophys Res Commun 2014, 445:651-655.

21. Gyugos M, Lendvai G, Kenessey I, Schlachter K, Halasz J, Nagy P, Garami M, Jakab Z, Schaff Z, Kiss A: MicroRNA expression might predict prognosis of epithelial hepatoblastoma. Virchows Arch 2014, 464:419-427.

22. Li J, Shi W, Gao Y, Yang B, Jing X, Shan S, Wang Y, Du Z: Analysis of microRNA expression profiles in human hepatitis $B$ virus-related hepatocellular carcinoma. Clin Lab 2013, 59:1009-1015.

23. Xiao F, Zhang W, Zhou L, Xie H, Xing C, Ding S, Chen K, Zheng S: microRNA-200a is an independent prognostic factor of hepatocellular carcinoma and induces cell cycle arrest by targeting CDK6. Oncol Rep 2013, 30:2203-2210.

24. Yu L, Ding GF, He C, Sun L, Jiang Y, Zhu L: MicroRNA-424 is down-regulated in Hepatocellular Carcinoma and suppresses cell migration and invasion through c-Myb. PLoS One 2014, 9:e91661.

25. Wang L, Yao M, Dong Z, Zhang Y, Yao D: Circulating specific biomarkers in diagnosis of hepatocellular carcinoma and its metastasis monitoring. Tumour Biol 2014, 35:9-20.
26. Yang Y, Gu X, Zhou M, Xiang J, Chen Z: Serum microRNAs: a new diagnostic method for colorectal cancer. Biomed Rep 2013, 1:495-498.

27. Sun L, Hu J, Xiong W, Chen X, Li H, Jie S: MicroRNA expression profiles of circulating microvesicles in hepatocellular carcinoma. Acta Gastroenterol Belg 2013, 76:386-392.

28. Fu Y, Wei X, Tang C, Li J, Liu R, Shen A, Wu Z: Circulating microRNA-101 as a potential biomarker for hepatitis $B$ virus-related hepatocellular carcinoma. Oncol Lett 2013, 6:1811-1815.

29. Ng EK, Li R, Shin WY, Siu JM, Ma ES, Kwong A: MicroRNA-143 is downregulated in breast cancer and regulates DNA methyltransferases 3A in breast cancer cells. Tumour Biol 2014, 35:2591-2598.

30. Naito Y, Sakamoto N, Oue N, Yashiro M, Sentani K, Yanagihara K, Hirakawa K, Yasui W: MicroRNA-143 regulates collagen type III expression in stromal fibroblasts of scirrhous type gastric cancer. Cancer Sci 2014, 105:228-235.

31. Schee K, Lorenz S, Worren MM, Gunther CC, Holden M, Hovig E, Fodstad O, Meza-Zepeda LA, Flatmark K: Deep sequencing the MicroRNA Transcriptome in Colorectal Cancer. PLoS One 2013, 8:e66165.

32. Liu SG, Qin XG, Zhao BS, Qi B, Yao WJ, Wang TY, Li HC, Wu XN: Differential expression of miRNAs in esophageal cancer tissue. Oncol Lett 2013, 5:1639-1642.

33. Masamune A, Nakano E, Hamada S, Takikawa T, Yoshida N, Shimosegawa T: Alteration of the microRNA expression profile during the activation of pancreatic stellate cells. Scand J Gastroenterol 2014, 49:323-331.

34. Zhang X, Liu S, Hu T, He Y, Sun S: Up-regulated microRNA-143 transcribed by nuclear factor kappa $B$ enhances hepatocarcinoma metastasis by repressing fibronectin expression. Hepatology 2009, 50:490-499.

35. Senanayake U, Das S, Vesely P, Alzoughbi W, Frohlich LF, Chowdhury P, Leuschner I, Hoefler G, Guertl B: miR-192, miR-194, miR-215, miR-200c and miR-141 are downregulated and their common target ACVR2B is strongly expressed in renal childhood neoplasms. Carcinogenesis 2012, 33:1014-1021.

36. White NM, Khella HW, Grigull J, Adzovic S, Youssef YM, Honey RJ, Stewart R, Pace KT, Bjarnason GA, Jewett MA, Evans AJ, Gabril M, Yousef GM: miRNA profiling in metastatic renal cell carcinoma reveals a tumour-suppressor effect for miR-215. Br J Cancer 2011, 105:1741-1749.

37. Gui J, Tian Y, Wen X, Zhang W, Zhang P, Gao J, Run W, Tian L, Jia X, Gao Y: Serum microRNA characterization identifies miR-885-5p as a potential marker for detecting liver pathologies. Clin Sci (Lond) 2011, 120:183-193.

38. Ishida H, Tatsumi T, Hosui A, Nawa T, Kodama T, Shimizu S, Hikita H, Hiramatsu N, Kanto T, Hayashi N, Takehara T: Alterations in microRNA expression profile in HCV-infected hepatoma cells: involvement of miR-491 in regulation of HCV replication via the PI3 kinase/Akt pathway. Biochem Biophys Res Commun 2011, 412:92-97

39. Chen Q, Ge X, Zhang Y, Xia H, Yuan D, Tang Q, Chen L, Pang X, Leng W, B F: Plasma miR-122 and miR-192 as potential novel biomarkers for the early detection of distant metastasis of gastric cancer. Oncol Rep 2014 31:1863-1870

\section{doi:10.1186/1746-1596-9-135}

Cite this article as: Zhang et al: Serum microRNA 143 and microRNA 215 as potential biomarkers for the diagnosis of chronic hepatitis and hepatocellular carcinoma. Diagnostic Pathology 2014 9:135

\section{Submit your next manuscript to BioMed Central and take full advantage of:}

- Convenient online submission

- Thorough peer review

- No space constraints or color figure charges

- Immediate publication on acceptance

- Inclusion in PubMed, CAS, Scopus and Google Scholar

- Research which is freely available for redistribution 